\title{
Hypogonadism and Erectile Dysfunction in Male Patients of Type 2 DM without CAD and With CAD in Indian Scenario
}

\author{
Authors \\ Dr Piyush Kumar ${ }^{1}$, Dr Dharam Prakash Bansal ${ }^{2}$, Dr Prashant Pathak ${ }^{3}$, \\ Dr Ankit Manglunia ${ }^{4}$, Dr Ritvik Agrawal $^{5}$ \\ ${ }^{1,3,4,5}$ PG Resident, Dept. of General Medicine, Mahatma Gandhi Medical College \& Hospitals, Jaipur, \\ Rajasthan \\ ${ }^{2}$ Associate Professor, Dept. of General Medicine, Mahatma Gandhi Medical College \& Hospitals, Jaipur, \\ Rajasthan
}

\begin{abstract}
AIM-: The present study is carried out to investigate hypogonadism using serum testosterone levels in male Type 2 diabetes mellitus (T2DM) subjects with and without coronary artery disease (CAD) and prevalence of erectile dysfunction in type 2 DM with and without CAD

MATERIAL AND METHODS: This was a cross-sectional study, conducted among 80 men (aged 30-70 years) with type 2 diabetes and 40 nondiabetic (aged 30-70 years) who visited medicine OPD of mahatma Gandhi hospital, Jaipur between Feb 2015 to March 2016. The patients' demographic characteristics were collected using a pre structured questionnaire. Duration of diabetes, smoking habits, family history, drug history, trauma history, any tumour or radiation history or history of chronic liver and kidney disease were collected. Venous blood sample was collected to test for total testosterone (TT), free testosterone (FT), serum lipids, and glycosylated haemoglobin (HbAlc).. In all men, the morning (08.00-10.00 hours) TT and FT levels were measured after an overnight fast. Normal levels of TT were taken as 300-1000 ng/dl and normal levels of FT as $9-40 \mathrm{pg} / \mathrm{ml}$. Presence and degree of ED was assessed by the validated international index of erectile Function-5 (IIEF-5) questionnaire. Erectile dysfunction was considered present when the IIEF-5 score was $\leq 21$.
\end{abstract}

RESULTS: $36.11 \%$ of type 2 DM with CAD subjects had low total testosterone as compared to type 2 DM without CAD (22.72\%) subjects. 61.11\% type 2 DM with CAD subjects had low free testosterone than $54.54 \%$ type 2 DM without CAD subjects. Total testosterone $(298.63 \pm 24.75)$ in patients with type 2 DM were significantly lower as compared to control $(383.81 \pm 58.36) \quad p<0.001$. Free testosterone $(7.61 \pm 2.12)$ in patients with type $2 \mathrm{DM}$ were significantly lower as compared to control $(11.17 \pm 2.34) p<0.001$.

CONCLUSION: We observed hypogonadism as indicated by low testosterone levels in a significant proportion of male T2DM subjects with CAD.

Erectile dysfunction was found to be more severe in DM2 with CAD. Thus erectile dysfunction can be a indicator of CAD in type $2 D M$ and correcting them early may prevent coronary artery disease.

KEYWORDS: Cardiovascular risk, coronary artery disease, diabetes, hypogonadism, testosterone.

\section{INTRODUCTION}

In recent years, low testosterone levels have been recognized to be closely associated with increased cardiovascular (CV) risk. ${ }^{1,2}$ Studies in the past have reported that testosterone deficiency is inversely associated with coronary intima-media 
thickness (CIMT), ${ }^{3,4}$ a surrogate marker for atherosclerosis which leads to the development of coronary artery disease (CAD). Inverse relationships between the serum testosterone level and cardiovascular risk factors, such as obesity, hypertension, dyslipidemia and insulin resistance, have been observed ${ }^{5-9}$. Cardiovascular disease is an important cause of morbidity and mortality in men with type 2 diabetes. In the population-based Osteoporotic Fractures in Men Study cohort from Sweden, men in the highest quartile of serum testosterone level had the lowest risk of cardiovascular events compared with men in the other three quartiles. When men with known CVD at baseline were excluded, the hazard remained ${ }^{10}$. Similar observations had been reported in Asians. In a prospective cohort of 171 middle-aged Japanese men with coronary risk factors without a previous history of CVD, low serum total testosterone was associated with a significant fourfold higher risk of cardiovascular events when comparing men from the lowest testosterone tertile with those in the highest tertile $(P<0.01)$, independent of coronary risk factors and endothelial dysfunction ${ }^{11}$.

Decrease in testosterone levels is also influenced by age, ${ }^{12}$ obesity, ${ }^{13}$ and insulin resistance (IR). ${ }^{14}$ Subjects with diabetes have been reported to have low serum testosterone levels as compared with the healthy individuals. ${ }^{15}$ Subjects with diabetes also possess a greater $\mathrm{CV}$ risk. ${ }^{16,17}$

This study is done to determine the relationship of low testosterone and erectile dysfunction in DM2 with CAD and DM2 without CAD.

\section{MATERIALS AND METHODS}

The study was conducted in 80 male subjects with diabetes mellitus type 2 and 40 non diabetic subjects age and sex matched, attending Diabetic OPD and admitted in medicine ward Mahatma Gandhi Hospital between March 2015 and February 2016 with official permission and ethical clearance given by ethical committee of Mahatma
Gandhi Medical College and Hospital, Jaipur, Rajasthan.

Patients with a known history of hypogonadism, panhypopituitarism, patients not willing for study, patients taking exogenous testosterone, patients with hyperthyroidism, or chronic debilitating disease, such as renal failure, cirrhosis, or HIV, were excluded from the study. The mean level of serum testosterone was calculated in various age and BMI groups and compared with controls.

TT was measured by fully automated bi directionally interfaced chemiluminescent immunoassay (CLIA) and FT was measured by radio immune assay (RIA), with an intra-assay coefficient of variation of $2.6 \%$ and an inter assay coefficient of variation of $4.3 \%$. Normal levels of TT were taken as 300-1000 $\mathrm{ng} / \mathrm{dl}$ and normal levels of FT as 9-40 pg/ml. Presence of diabetes mellitus was defined as per American Diabetes Association Criteria. ${ }^{2011}$

Presence and degree of ED was assessed by the validated international index of erectile Function-5 (IIEF-5) questionnaire. Erectile dysfunction was considered present when the IIEF-5 score was $\leq$ 21.

\section{Statistical Method}

For different qualitative parameters mean and standard deviation calculated.

To compare the means between two groups, student unpaired ' $t$ ' test is used. Level of significance is taken as $\mathrm{p}<0.05$.

Chi square test is used to find the association between two qualitative variables.

Statistical analysis

The data was coded and entered into Microsoft Excel spreadsheet. Analysis was done using SPSS version 20 (IBM SPSS Statistics Inc., Chicago, Illinois, USA) Windows software program. The variables were assessed for normality using the Kolmogorov Smirnov test. Descriptive statistics included computation of means and standard deviations. Level of significance was set at $P \leq 0.05$. 


\section{RESULTS}

Table 1: Distribution According to Age

\begin{tabular}{|l|c|c|}
\hline Age in Years & Case N (\%) & Control N (\%) \\
\hline $30-40$ & $15(18.75 \%)$ & $10(25 \%)$ \\
\hline $41-50$ & $32(40 \%)$ & $15(37.5 \%)$ \\
\hline $51-60$ & $28(35 \%)$ & $12(30 \%)$ \\
\hline$>60$ & $5(6.25 \%)$ & $3(7.25 \%)$ \\
\hline Total & 80 & 40 \\
\hline
\end{tabular}

Table shows age distribution among case and control groups. Most of subjects were from 41-60 year age groups among both case (75\%) and control $(67.5 \%)$ groups.

Table 2 Distribution of case subject

\begin{tabular}{|l|c|c|}
\hline & $\begin{array}{c}\text { Diabetes Mellitus Type2 With Coronary } \\
\text { Artery Disease }\end{array}$ & $\begin{array}{c}\text { Diabetes Mellitus Type2 Without Coronary } \\
\text { Artery Disease }\end{array}$ \\
\hline No. of Cases & 36 & 44 \\
\hline
\end{tabular}

Table revealed only Diabetes Mellitus Type 2 cases in which 36 subjects were Diabetes Mellitus Type 2 with coronary artery disease and 44 were from Diabetes Mellitus Type 2 without coronary artery disease

Table 3 General Characteristics of the Study Variables

\begin{tabular}{|l|c|c|c|}
\hline Variables Case & Control & P value \\
\hline AGE (mean in years) & $48.32 \pm 8.25$ & $47.02 \pm 9.54$ & 0.44 \\
\hline Body mass index (mean in kg/m ${ }^{2)}$ & $27.11 \pm 4.603$ & $27.07 \pm 3.608$ & 0.96 \\
\hline $\begin{array}{l}\text { Systolic Pressure } \\
\text { (mean in mm Hg) }\end{array}$ & $127.75 \pm 11.202$ & $120.4 \pm 7.24$ & $<0.001(\mathrm{~S})$ \\
\hline $\begin{array}{l}\text { Diastolic Blood Pressure } \\
\text { (mean in mm Hg) }\end{array}$ & $80.25 \pm 5.63$ & $78.6 \pm 3.62$ & 0.09 \\
\hline $\begin{array}{l}\text { Dyslipidemia } \\
\text { (HDL<40 mg/dl, TG>150mg/dl) }\end{array}$ & $\mathrm{n}=72$ & $\mathrm{n}=14$ & $0.01(\mathrm{~S})$ \\
\hline Smoking & $\mathrm{n}=24$ & $\mathrm{n}=8$ & $0.01(\mathrm{~S})$ \\
\hline Alcohol & $\mathrm{n}=9$ & $\mathrm{n}=4$ & 0.22 \\
\hline Family history & & $\mathrm{n}=6$ & $0.01(\mathrm{~S})$ \\
\hline
\end{tabular}

Table provided general characteristics of the study variables. Systolic blood pressure $(127.75,120.4)$, dyslipidemia $(72,14)$, smoking $(24,8)$ and family history $(40,6)$ showed statistically significant results among subjects with type $2 \mathrm{DM}$ and control groups respectively.

Table 4 Risk factor for CAD

\begin{tabular}{|l|c|c|c|}
\hline & $\begin{array}{c}\text { Case } \\
\mathrm{n}(\%)\end{array}$ & $\begin{array}{c}\text { Control } \\
\mathrm{n}(\%)\end{array}$ & P value \\
\hline Age $(>45 y e a r s)$ & $46(67.6)$ & $22(32.4)$ & 0.79 \\
\hline BODY MASS INDEX $\left(>30 \mathrm{~kg} / \mathrm{m}^{2}\right)$ & $26(72.2)$ & $10(27.8)$ & 0.39 \\
\hline HYPERTENSION & $13(16.2)$ & $1(2.5)$ & $0.002(\mathrm{~S})$ \\
\hline Smoking & $1(100)$ & $8(88.9)$ & $0.01(\mathrm{~S})$ \\
\hline Alcohol & $9(69.2)$ & $4(30.8)$ & $0.01(\mathrm{~S})$ \\
\hline Family history & $40(87)$ & $6(13)$ & $<0.001(\mathrm{~S})$ \\
\hline $\begin{array}{l}\text { DYSLIPIDEMIA } \\
(\text { HDL <40mg/dl, TG>150mg/dl) }\end{array}$ & $72(90)$ & $14(35)$ & $0.001(\mathrm{~S})$ \\
\hline
\end{tabular}




\section{JMSCR Vol||05||Issue||06||Page 23856-23863||June}

Table reveals the risk factors for CAD among the study groups. Cases showed more risk with hypertension (16.2), alcohol (69.2), dyslipidemia (90) family history (87) as compared to control which is statistically significant. Age (67.6) and BMI (72.2) didn't have effect on risk factors for CAD which provide statistically non- significant results

Table 5 Relationship of DM Patients with and without CAD with BMI $\left(\mathrm{kg} / \mathrm{m}^{2}\right)$

\begin{tabular}{|l|c|c|c|c|c|}
\hline \multirow{2}{*}{} & \multicolumn{3}{|c|}{ BMI No. of participants (\%) } & \multirow{2}{*}{ P } \\
\cline { 2 - 5 } & $<18.5$ & $18.5-24.9$ & $25-29.9$ & $>30$ & value \\
\hline DM2 without CAD & $3(3.75 \%)$ & $15(18.75 \%)$ & $14(17.5 \%)$ & $12(15 \%)$ & \multirow{2}{*}{0.348} \\
\hline DM2 with CAD & $1(1.25 \%)$ & $7(8.75 \%)$ & $14(17.5 \%)$ & $14(17.5 \%)$ & \\
\hline Total & $4(5 \%)$ & $22(27.5 \%)$ & $28(35 \%)$ & $26(32.5 \%)$ & \\
\hline
\end{tabular}

Table showed that percentage of obese (15\%, $17.5 \%)$, overweight $(17.5 \%, 17.5 \%)$ in DM2 with $\mathrm{CAD}$ and DM2 without CAD were almost similar.

Table 6 Comparison of Testosterone Profile

\begin{tabular}{|l|c|c|c|}
\hline & $\begin{array}{c}\text { Case } \\
\text { Mean } \pm \text { std Deviation }\end{array}$ & $\begin{array}{c}\text { Control } \\
\text { Mean } \pm \text { std Deviation }\end{array}$ & P value \\
\hline Total Testosterone (ng/dl) & $298.63 \pm 24.75$ & $383.81 \pm 58.36$ & $<0.001(\mathrm{~S})$ \\
\hline Free Testosterone (pg/dl) & $7.61 \pm 2.12$ & $11.17 \pm 2.34$ & $<0.001(\mathrm{~S})$ \\
\hline International Index Erectile Function -5 Score & $14.62 \pm 5.39$ & $23.15 \pm 3.70$ & $<0.001(\mathrm{~S})$ \\
\hline
\end{tabular}

Table showed comparison of testosterone profile among case and control group. Total testosterone, free testosterone and International Index Erectile Function Score (IIEF-5) in case (298.63, 7.61,
14.62) and control $(383.81,11.17,23.15)$ group respectively showed statistically significant results.

Table 7 Comparison of testosterone profile in DM2 with CAD ,DM2 without CAD and nondiabetic controls

\begin{tabular}{|l|c|c|c|}
\hline & DM2 WITH CAD & DM2 WITHOUT CAD & NONDIABETIC (CONTROL) \\
\hline $\begin{array}{l}\text { TOTAL } \\
\text { TESTOSTERONE }\end{array}$ & 263 & 302 & 383.81 \\
\hline FREE TESTOSTERONE & 7.07 & 7.65 & 11.17 \\
\hline
\end{tabular}

Table shows that total and free testosterone were significantly lower in DM2 with CAD as compared to non diabetec and DM2 without CAD

Table 7 Comparison of Study of Erectile Dysfunction in DM2 without CAD and DM2 with CAD among Cases

\begin{tabular}{|l|c|c|c|c|c|}
\hline \multirow{2}{*}{} & \multicolumn{5}{|c|}{ IIEF-5 Score } \\
\cline { 2 - 6 } & $22-25$ & $17-21$ & $12-16$ & $8-11$ & $5-7$ \\
\hline DM2 without CAD & 15 & 12 & 12 & 3 & 2 \\
\hline DM2 with CAD & 0 & 1 & 14 & 14 & 7 \\
\hline Total & 15 & 13 & 26 & 17 & 9 \\
\hline
\end{tabular}

Table showed Comparison of study of erectile dysfunction in DM2 and DM2 with CAD among cases. Case of DM2 with CAD had more severe erectile dysfunction as compared to DM2 without CAD which had statistically significant results. 


\section{DISCUSSION}

\section{Distribution According to Age}

It has been documented in the literature that serum testosterone levels decreased with age. After age of 30 years $1-2 \%$ of serum testosterone levels decrease with every year as a part of normal aging process. But few recent studies have shown that decrease in serum testosterone level with age is not normal (Guay et $\mathrm{al}^{18}, 2003$ ). The mean age in the present study was $48.32 \pm 8.20$ in case group and 47.02 \pm 9.42 in control group. Majority of the cases $(40.1 \%)$ and controls $(37.5 \%)$ were in age groups of 41-50 yrs. The mean age in the study by Koopman et $\mathrm{al}^{19}$ (2005) was $46.01 \pm 1.27 \mathrm{yrs}$. According to Gale et $\mathrm{al}^{20}$ (2010), the average age of onset of diabetes mellitus type 2 in Indian population is $42.5 \mathrm{yrs}$. The present study was comparable to that seen in Koopman et al ${ }^{19} 2005$ study (46.01 years).

\section{Risk Factor of CAD and their Relationship with Diabetes Mellitus Type 2}

In our study significant correlation with HTN (16.2\%), alcohol (68.2\%), dyslipidemia (90\%), and family history of CAD and DM2 (87\%) was seen with case as compared to control groups. Age and BMI shown no effect as risk factor for CAD which provide statistically non significant results.

In our study, it was observed that total cardiovascular risk was less in patients without ED. Moreover, as severity of ED increased, total cardiovascular risk also increased. Various other workers have reported the correlation between $\mathrm{ED}$, cardiovascular risk and other risk factors such as HT, dyslipidemias and obesity. ${ }^{21}$

In 2002, Jackson et al, concluded that erectile dysfunction and cardiovascular disease share several risk factors that are similar and commonly coexist. ED in asymptomatic man may be a marker for underlying coronary artery disease. ${ }^{22}$

In 2003, Roth et al, ${ }^{23}$ studied 1412 Israeli men and found that ED and cardiovascular disease share common risk factors and may be aggravated by medical treatment for reducing them. They concluded that ED is common among patients who are at high risk for cardiovascular disease because of diabetes and or hypertension

In 2003, Mota et $\mathrm{al}^{24}$ studied 310 male diabetic patients and observed that ED showed a positive correlation with obesity, stroke, arteriopathy, retinopathy and smoking, but it was not correlated to type of diabetes mellitus, duration of diabetes $<10$ years, hypertension, IHD, nephropathy, dyslipidemia and alcohol consumption.

\section{Correlation of Dyslipidemia and CAD and Erectile Dysfunction}

Epidemiologic data also suggest that hypercholesterolemia and perhaps coronary atherosclerosis itself are risk factors for ischemic stroke. Specific indices of dyslipidemia are elevated levels of plasma triglyceride (>150 $\mathrm{mg} / \mathrm{dl})$, low levels of HDL-C $(<40 \mathrm{mg} / \mathrm{dl})$ and normal LDL-C levels but smaller and denser particles which increase their atherogenic potential $^{25}$ the present finding found that cholesterol and triglycerides were elevated in DM2 patients. Also there were a statistically significant differences in triglycerides and HDL-C among DM2 patients and controls $(\mathrm{p}<0.05)$. The observed dyslipidemia among DM2 patients may be one of the risk factors that increases incidence of ED among those patients.

Hyperlipidemia may impair erectile function by affecting endothelial and smooth muscle cells of the penis. It was clear from the study that Dyslipidemia is linked to ED. ${ }^{26}$ Epidemiological studies have shown that elevated serum cholesterol and reduced HDL-C levels are associated with an increased risk of $\mathrm{ED}^{27}$ According to present findings, dyslipidemia was more prevalent among DM2 patients than controls. These results coincide with previous studies in that dyslipidemia is a risk factor of ED and is linked to it. In addition, ED was correlated with duration of DM2 and its complications $(\mathrm{p}<0.05)$, this may be attributed to the fact that endothelial dysfunction which characterizes diabetic patients is leading cause of ED among DM2 patients. 


\section{Distribution According to Serum Testosterone}

The Mean serum total testosterone in DM2 with CAD and without CAD was $(263,302)$ respectively and in control group was 383.81 . The difference was statistically significant. The Mean serum free testosterone in DM2 with and without CAD was 7.07,7.65 and in control group was 11.17. In present study, 23 out of 80 type 2 diabetes mellitus patients $(28.75 \%)$ and 8 out of 40 controls (25\%) had low level of total testosterone in serum, whereas 46 out of 80 diabetes mellitus patients (57.5\%) and 8 out of 40 controls $(25 \%)$ had low levels of free testosterone. The difference was statistically significant.

In the study by Ernani et $\mathrm{al}^{28}$ (2005), low levels of serum total testosterone was found in patients with diabetes mellitus (34\%) when compared to healthy control subjects (23\%). In the study by

Kapoor et $\mathrm{al}^{29}$ (2007), low levels of total testosterone was found in $(25 \%)$ of patients with diabetes mellitus. In the study by Ernaniet $\mathrm{al}^{28}(2005)$ level of free testosterone was decreased in $46 \%$ of diabetics as compared to $24 \%$ in nondiabetics. In the study by Kooparet $\mathrm{al}^{29}$ (2007), $42 \%$ of patients with DM type 2 had low levels of serum free testosterone.

In the present study the low levels of serum total and free testosterone in DM2 patients and control group were comparable to other previous studies.

A meta-analysis study showed that low testosterone levels are associated with increased $\mathrm{CV}$ risk and mortality. ${ }^{30}$ This analysis also showed that testosterone replacement therapy in subjects with hypogonadism moderates metabolic components associated with CV risk. ${ }^{30}$ Significant testosterone deficiency observed in diabetes subjects with CAD raises the important issue whether these subjects should be given testosterone replacement therapy in an attempt to reduce $\mathrm{CV}$ risk. This notion is also based on the findings of a recent retrospective study involving over 83,000 veterans. ${ }^{31}$ Results of this study showed that normalization of TT levels with testosterone replacement therapy leads to a significant lowering of all causes of mortality, MI risk, and stroke. ${ }^{31}$
Study of Erectile Dysfunction in Patient of DM2 In the present study, out of 80 diabetic male, the erectile dysfunction was present in $65(81.25 \%)$ patients. Out of which, 14 (17.5\%) had mild ED and $30(37.5 \%)$ patients had moderate and (26.25\%) severe ED. Erectile dysfunction was found to be more severe in DM2 with CAD than without CAD.

Schiavi et $\mathrm{al}^{32}$, studied 40 diabetic men, free from other illness or drugs that could affect sexual capacity and 40 age-matched healthy control subjects. ED was present in $77 \%$ of patients. Sundaram et $\mathrm{al}^{33}$, reported that in diabetic patients, the prevalence of ED was $66 \%$. Ledda et $\mathrm{al}^{34}$, reported that $\mathrm{ED}$ was very common among diabetic patients.

\section{CONCLUSION}

The present study finds testosterone deficiency in a significant proportion of male T2DM subjects particularly those with evidence of $\mathrm{CV}$ disease. Low testosterone levels could contribute to a significantly higher cardiovascular risk in subjects with T2DM.

\section{REFERENCES}

1. Krysiak R, Gilowski W, Okopien B. The effect of testosterone on cardiovascular risk factors in men with type 2 diabetes and late-onset hypogonadism treated with metformin or glimepiride. Pharmacol Rep. 2016;68:75-9. [PubMed]

2. Martínez-Jabaloyas JM. DE-SDT Study Group. Testosterone deficiency in patients with erectile dysfunction: When should a higher cardiovascular risk be considered? J Sex Med. 2014;11:2083-91.[PubMed]

3. Muller M, van den Beld AW, Bots ML, Grobbee DE, Lamberts SW, van der Schouw YT. Endogenous sex hormones and progression of carotid atherosclerosis in elderly men. Circulation. 2004; 109:2074-9.[PubMed]

4. Svartberg J, von Mühlen D, Mathiesen E, Joakimsen O, Bønaa KH, Stensland-Bugge E. Low testosterone levels are associated 
with carotid atherosclerosis in men. J Intern Med. 2006;259:576-82. [PubMed]

5. Haffner SM, Shaten J, Stern MP, et al. Low levels of sex hormone-binding globulin and testosterone predict the development of non-insulin-dependent diabetes mellitus in men. MRFIT Research Group. Multiple Risk Factor Intervention Trial. Am J Epidemiol. 1996;143:889897. [PubMed]

6. Stellato RK, Feldman HA, Hamdy O, et al. Testosterone, sex hormone-binding globulin, and the development of type 2 diabetes in middle-aged men: prospective results from the Massachusetts male aging study. Diabetes Care. 2000;23:490-494. [PubMed]

7. Tsai EC, Matsumoto AM, Fujimoto WY, et al. Association of bioavailable, free, and total testosterone with insulin resistance: influence of sex hormone-binding globulin and body fat. Diabetes Care. 2004;27:861868. [PubMed]

8. van den Beld AW, de Jong FH, Grobbee DE, et al. Measures of bioavailable serum testosterone and estradiol and their relationships with muscle strength, bone density, and body composition in elderly men. J Clin Endocrinol Metab. 2000;85:3276-3282. [PubMed]

9. Zmuda JM, Cauley JA, Kriska A, et al. Longitudinal relation between endogenous testosterone and cardiovascular disease risk factors in middle-aged men. A 13-year follow-up of former Multiple Risk Factor Intervention Trial participants. Am J Epidemiol. 1997;146:609-617. [PubMed]

10. Ohlsson C, Barrett-Connor E, Bhasin S, et al. High serum testosterone is associated with reduced risk of cardiovascular events in elderly men the mros (osteoporotic fractures in men) study in sweden. J Am Coll Cardiol. 2011;58:16741681. [PubMed]

11. Akishita M, Hashimoto M, Ohike Y, et al. Low testosterone level as a predictor of cardiovascular events in Japanese men with coronary risk factors. Atherosclerosis. 2010;210:232-236. [PubMed]

12. Ferrini RL, Barrett-Connor E. Sex hormones and age: A cross-sectional study of testosterone and estradiol and their bioavailable fractions in communitydwelling men. Am J Epidemiol. 1998;147: 750-4. [PubMed]

13. Wang C, Jackson G, Jones TH, Matsumoto AM, Nehra A, Perelman MA, et al. Low testosterone associated with obesity and the metabolic syndrome contributes to sexual dysfunction and cardiovascular disease risk in men with type 2 diabetes. Diabetes Care. 2011;34:166975. [PMC free article] [PubMed]

14. Pitteloud N, Hardin M, Dwyer AA, Valassi E, Yialamas M, Elahi D, et al. Increasing insulin resistance is associated with a decrease in Leydig cell testosterone secretion in men. J Clin Endocrinol Metab. 2005;90:2636-41. [PubMed]

15. Kapoor D, Aldred H, Clark S, Channer KS, Jones TH. Clinical and biochemical assessment of hypogonadism in men with type 2 diabetes: Correlations with bioavailable testosterone and visceral adiposity. Diabetes Care. 2007;30:9117. [PubMed]

16. Martín-Timón I, Sevillano-Collantes C, Segura-Galindo A, Del Cañizo-Gómez FJ. Type 2 diabetes and cardiovascular disease: Have all risk factors the same strength? World J Diabetes. 2014;5:44470.[PMC free article] [PubMed]

17. Tan CE, Chew LS, Chio LF, Tai ES, Lim HS, Lim SC, et al. Cardiovascular risk factors and LDL subfraction profile in type 2 diabetes mellitus subjects with good glycaemic control. Diabetes Res Clin Pract. 2001;51:107-14. [PubMed]

18. Harman SM, Metter EJ, Tobin JD, Pearson $\mathrm{J}$, Blackman MR. Longitudinal effects of aging on serum total and free testosterone levels in healthy men. Baltimore 
Longitudinal Study of Aging. The Journal of Clinical Endocrinology Metabolism. 2001;86:724-31.

19. Shimokata H, Muller DC, Fleg JL, Sorkin J, Ziemba AW, Andres R. Age as independent determinant of glucose tolerance. Diabetes. 1991;40:44-51.

20. Abate N, Haffner SM, Garg A, Peshock RM, Grundy SM. Sex steroid hormones, upper body obesity, and insulin resistance. The Journal of Clinical Endocrinology Metabolism. 2002;87:4522-7.

21. Kapoor D, Aldred H, Clark S, Channer KS, Jones TH. Clinical and biochemical assessment of hypogonadism in men with type 2 diabetes: correlations with bioavailable testosterone and visceral adiposity. Diabetes Care. 2007;30:912-7.

22. Dhindsa S, Prabhakar S, Sethi M, Bandyopadhyay A, Chaudhuri A, Dandona P. Frequent occurrence of hypogonadotropic hypogonadism in type 2 diabetes. The Journal of Clinical Endocrinology Metabolism. 2004;89:5462-8.

23. Nieschlag E, Swerdloff R, Behre HM, Gooren LJ, Kaufman JM, Legros JJ, Lunenfeld B, Morley JE, Schulman C, Wang C, Weidner W. Investigation, treatment, and monitoring of late-onset hypogonadism in males: ISA, ISSAM, and EAU recommendations. Journal of Andrology. 2006 Mar 4;27(2):135-7.

24. Mohan V, Sandeep S, Deepa R, Shah B. Epidemiology of type 2 diabetes: Indian scenario. Indian Journal of Medicine. 2007;125:217-320.

25. Knuiman MW, Welborn TA, McCann VJ, Stanton KG, Constable IJ. Prevalence of diabetic complications in relation to risk factors. Diabetes. 1986;35:1332-9.

26. Rema M, Ponnaiya M, Mohan V. Prevalence of retinopathy in non insulin dependent diabetes mellitus at a diabetes centre in southern India. Diabetes research and clinical practice. 1996 Sep 30;34(1):29-36.
27. Harris MI, Klein R, Welborn TA, Knuiman MW. National Diabetes Data Group, National Institute of Diabetes and Digestive and Kidney disease, Bethesda, Maryland. Diabetes care. 1992;15:815-9.

28. Goodman-Gruen D, Barrett-Connor E. Sex differences in the association of endogenous sex hormone levels and glucose tolerance status in older men and women. Diabetes Care. 2000;23:912-8.

29. Haffner SM, Shaten J, Stern MP, Smith GD, Kuller L. Low levels of sex hormone binding globulin and testosterone predict the development of non-insulin dependent diabetes mellitus in men. MRFIT Research Group. Multiple Risk Factor Intervention Trial. American Journal of Epidemiology. 1996;143:889-97.

30. Corona G, Rastrelli G, Monami M, Guay A, Buvat J, Sforza A, et al. Hypogonadism as a risk factor for cardiovascular mortality in men: A meta-analytic study. Eur J Endocrinol. 2011;165:687-701. [PubMed]

31. Sharma R, Oni OA, Gupta K, Chen G, Sharma M, Dawn B, et al. Normalization of testosterone level is associated with reduced incidence of myocardial infarction and mortality in men. Eur Heart J. 2015;36:2706-15. [PubMed]

32. El-Sakka AI, Hassoba HM, Sayed HM, Tayeb KA. Pattern of endocrinal changes in patients with sexual dysfunction. Journal of Sexual Medicine. 2005;2;551-8.

33. American Diabetes Association (ADA); Clinical Practice Guidelines Expert Committee; American Diabetes Association; Clinical Practice Guidelines for the Prevention and Management of Diabetes. Diabetes. 2003;27(2);1-152.

34. Health Central; Dyslipidemia Causes Erectile Dysfunction, 2009. http://www.health central.com/erectiledysfunction/c/936577/81208/dys/. 